\title{
Lifestyle Factors and Indices of Kidney Function in the Framingham Heart Study
}

\author{
Meredith C. Foster $^{a-c}$ Shih-Jen Hwang ${ }^{a, b}$ Joseph M. Massaro ${ }^{d}$ \\ Paul F. Jacques $^{e}$ Caroline S. Fox $^{a, b, f}$ Audrey Y.Chu ${ }^{a, b, g}$ \\ ${ }^{a}$ National Heart, Lung, and Blood Institute's Framingham Heart Study, Framingham, Mass., ${ }^{\mathrm{b}}$ Center for Population \\ Studies, National Heart, Lung, and Blood Institute, National Institutes of Health, Bethesda, Md., 'Tufts Medical \\ Center, Boston, Mass., dDepartment of Biostatistics, Boston University School of Public Health, Boston, Mass., \\ e US Department of Agriculture Human Nutrition Research Center on Aging, Tufts University, Boston, Mass., \\ ${ }^{f}$ Division of Endocrinology and Metabolism, Brigham and Women's Hospital, Harvard Medical School, Boston, Mass., \\ 'Division of Preventive Medicine, Brigham and Women's Hospital, Harvard Medical School, Boston, Mass., USA
}

\section{Key Words \\ Lifestyle factors - Dietary quality · Physical activity . Smoking · Alcohol intake · Chronic kidney disease . Epidemiology}

\begin{abstract}
Background and Objectives: Lifestyle characteristics are modifiable factors that could be targeted as part of chronic kidney disease (CKD) prevention. We sought to determine the association of lifestyle characteristics with incident estimated glomerular filtration rate (eGFR) $<60 \mathrm{ml} / \mathrm{min} / 1.73 \mathrm{~m}^{2}$ and rapid eGFR decline in older adults in the United States. Methods: Prospective cohort study of Framingham Offspring participants with baseline eGFR $<60 \mathrm{ml} / \mathrm{min} / 1.73 \mathrm{~m}^{2}$ $(\mathrm{n}=1,802)$ who attended the seventh (1998-2001; baseline) and eighth (2005-2008; follow-up) examinations (mean age $=59$ years, $54.8 \%$ women). Predictors included measures of diet quality, physical activity, alcohol intake, and current smoking status assessed during baseline. Outcomes were based on creatinine-based eGFR at baseline and follow-up and included incident eGFR $<60 \mathrm{ml} / \mathrm{min} / 1.73 \mathrm{~m}^{2}$ (at followup) and rapid eGFR decline (annual eGFR decrease $\geq 3 \mathrm{ml} /$ $\mathrm{min} / 1.73 \mathrm{~m}^{2}$ ). Results: Over an average follow-up of 6.6 years, $9.5 \%(n=171)$ of participants developed incident eGFR $<60$.
\end{abstract}

A trend was observed across quartiles of diet quality, with higher levels of diet quality associated with a decreased odds ratio (OR) of incident eGFR $<60$ ( $p$ trend $=0.045$ ). Higher diet quality was associated with decreased odds of rapid eGFR decline ( $p$ trend $=0.03$ ) and was attenuated with additional adjustment ( $p$ trend $=0.07$ ). In sensitivity analysis for rapid eGFR decline using a secondary definition (annual eGFR decrease $\geq 3$ and incident eGFR $<60$ ), diet associations remained significant with additional adjustment $(p$ trend $=$ 0.04). No associations were observed with physical activity, smoking status, or alcohol intake with incident eGFR $<60$ or rapid eGFR decline (all $p>0.19$ ). Conclusions: Higher diet quality may be associated with a decreased risk of incident eGFR $<60 \mathrm{ml} / \mathrm{min} / 1.73 \mathrm{~m}^{2}$, and rapid eGFR decline. Whether adherence to a healthy diet can prevent reduction in kidney function warrants further study.

(c) 2015 National Institutes of Health (NIH) Published by S. Karger AG, Basel

\section{Introduction}

Chronic kidney disease (CKD) affects over 26 million adults in the United States and its incidence is continuing to increase [1]. CKD is a risk factor for cardiovascular disease morbidity and mortality [2-4] and several es-

\begin{tabular}{ll}
\hline KARGER 125/\% & $\begin{array}{l}\text { ○ 2015 National Institutes of Health (NIH) } \\
\text { Published by S. Karger AG, Basel } \\
0250-8095 / 15 / 0415-0267 \$ 39.50 / 0\end{array}$ \\
$\begin{array}{l}\text { E-Mail karger@karger.com } \\
\text { www.karger.com/ajn }\end{array}$ &
\end{tabular}

Audrey Y. Chu, PhD

$73 \mathrm{Mt}$. Wayte Ave Suite \#2 Framingham, MA 01702 (USA)

E-Mail audrey.chu@nih.gov 
tablished cardiovascular risk factors are also risk factors for CKD, including diabetes, hypertension, and obesity [5]. Obesity is of particular interest in relation to CKD. In addition to being an established risk factor for the development of cardiovascular and metabolic diseases [6, 7], obesity is a common condition in the United States [8] that can be modified through lifestyle interventions [9]. A growing body of evidence supports the role of both generalized and central obesity in the development of CKD [5, 10-15] and microalbuminuria [16-20]. Several modifiable lifestyle factors, including physical activity, smoking, and diet factors, are associated with the development of obesity and obesity-related disease and may also be associated with the development of CKD, potentially through obesity-related pathways. Potential mechanisms related to lifestyle factors and ectopic fat accumulation are also of interest, as we have previously observed that high renal sinus fat is independently associated with hypertension and chronic kidney disease [21].

Several studies have investigated the association of lifestyle factors and the development of kidney disease or renal function decline; the results for some lifestyle factors are inconsistent and few have investigated the impact of overall dietary patterns $[5,22-36]$. Thus, the primary aim of our study was to evaluate the association of potentially modifiable lifestyle factors with the development of incident estimated glomerular filtration rate (eGFR) $<60$ $\mathrm{ml} / \mathrm{min} / 1.73 \mathrm{~m}^{2}$, and rapid renal function decline in the Framingham Offspring cohort. Further, we sought to determine if such associations persisted after adjustment for body mass index (BMI) as a measure of overall adiposity; we also tried to determine the presence of other cardiometabolic conditions associated with incident eGFR $<60$. Through this analysis, we aimed at identifying lifestyle factors that could be targeted as part of an approach to prevent kidney function decline.

\section{Materials and Methods}

\section{Study Sample}

The original Framingham Heart Study cohort was established in 1948 and consisted of 5,209 women and men from Framingham, Massachusetts. In 1971, the Framingham Offspring cohort was established and consisted of 5,124 women and men who were children or the spouses of children from the original cohort. For the incident eGFR $<60$ sample, offspring participants who attended the seventh (1998-2001) and eighth (2005-2008) examination cycles were eligible for the present analysis $(n=2,869)$. Participants with missing serum creatinine measurements at either exam $(n=165)$, missing dietary data $(n=722)$, missing data on baseline hypertension, diabetes, or proteinuria $(n=18)$, or with eGFR $<60$ at baseline $(n=162)$ were excluded, leaving a study sample of 1,802 offspring participants. There were no differences in development of eGFR $<60$ at follow-up or lifestyle characteristics (dietary intake, physical activity, smoking, or alcohol intake) at baseline. However, participants excluded due to missing dietary data were more likely to have hypertension and diabetes, suggesting that these participants were likely to be less healthy. For rapid eGFR decline, participants with baseline eGFR $<60$ were not excluded, for a sample size of 1,964 participants. The study was approved by the institutional review boards of the Boston University Medical Center. All subjects provided written informed consent.

\section{Exposure Assessment}

Dietary intakes were assessed using the Harvard semi-quantitative food frequency questionnaire (FFQ) [37]. The FFQ consists of a list of foods with a standard serving size and a selection of 9 frequency categories ranging from never or $<1$ serving/month to $\geq 6$ servings/day. Participants were asked to report their frequency of consumption of each food item during the past year. Participants could also add up to three additional foods that are important components of their diets but are not listed on the questionnaire. Information on nutrient supplement use was also obtained by the FFQ. Dietary information was judged as unreliable and excluded from further study if reported energy intakes were $<600$ $\mathrm{kcal} /$ day or $>4,000 \mathrm{kcal} /$ day (women) or $>4,200 \mathrm{kcal} /$ day (men) or if $>12$ food items were left blank. Out of the $n=3,539$ participants in the FHS Offspring Study at baseline, $\mathrm{n}=414(11.7 \%)$ had no FFQ data and $n=95(2.7 \%)$ had unreliable diet data.

Diet quality was assessed using the Dietary Guidelines Adherence Index (DGAI), a previously validated index that assesses adherence to key dietary recommendations in the 2005 Dietary Guidelines for Americans (DGA), as previously described [38]. In brief, the DGAI is reported on a $0-20$ scale based on adherence to 20 energy-specific food and nutrient recommendations [38], with higher DGAI scores representing higher diet quality. As diet information was collected during the seventh examination cycle for offspring participants (through the FFQ), prior to the release of these guidelines, the DGAI is a measure of overall consistency of baseline diet with these recommendations in the 2005 DGA. Physical activity was assessed using a physical activity index (PAI). The PAI that takes into account the average number of hours/day at varying levels of activity intensity based on self-report, with higher scores representing higher levels of usual physical activity [39]. Alcohol intake was assessed using a physicianadministered questionnaire and categorized into three intake groups: none (0 drinks/week), low-to-moderate (1-7 drinks/ week in women and 1-14 drinks/week in men), and high intake ( $>7$ drinks/week in women and $>14$ drinks/week in men) [40]. Current smoking was defined as smoking $\geq 1$ cigarette/day in the past year.

\section{Outcome Assessment}

Serum creatinine was measured using the modified Jaffe method from fasting blood samples collected during the seventh and eighth exams (inter-assay coefficient of variation (CV) of $2.8 \%$ and intra-assay $\mathrm{CV}$ of $4.0 \%)$. Serum creatinine measures can vary widely across different laboratories. Therefore, we calibrated serum creatinine values through a two-step process: (1) calibration of $\mathrm{Na}$ - 
Table 1. Baseline characteristics of the study sample of offspring cohort participants who had eGFR $\geq 60 \mathrm{ml} / \mathrm{min} / 1.73 \mathrm{~m}{ }^{2}$ at baseline by development of incident $\mathrm{eGFR}<60 \mathrm{ml} / \mathrm{min} / 1.73 \mathrm{~m}^{2}$ at follow-up

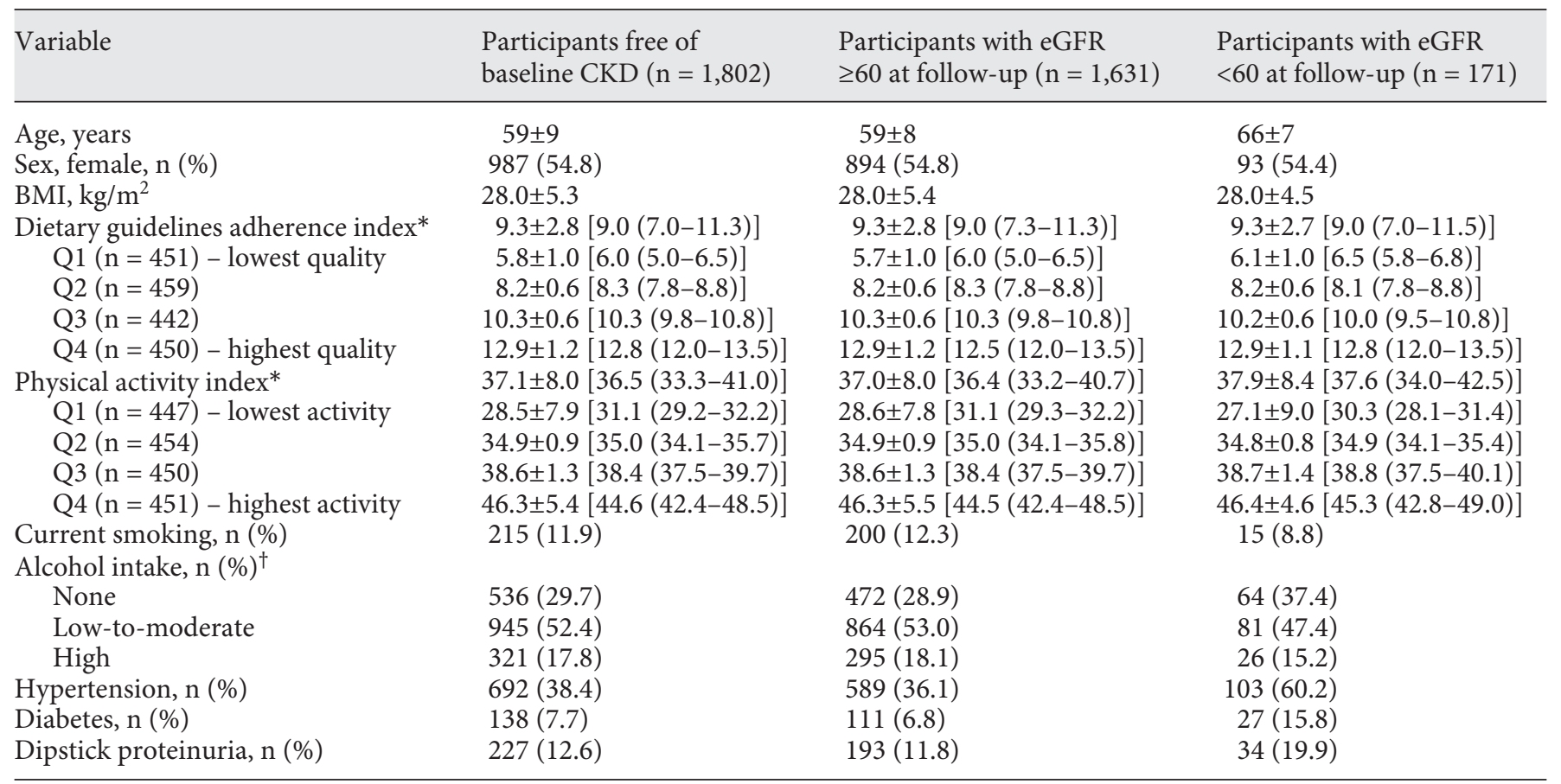

Continuous characteristics are presented as mean \pm standard deviation. * Median and interquartile range [median (IQR)] are also provided for dietary guidelines adherence index and physical activity index. ${ }^{\dagger}$ Alcohol intake defined as: none $=0$ drinks/week; low-to-moderate $=1-7$ drinks/week in women and 1-14 drinks/week in men; high = > 7 drinks/week in women and $>14$ drinks/week in men. Q = Quartiles.

tional Health and Nutrition Examination Survey III (NHANES III) creatinine values to the Cleveland Clinic Laboratory resulting in a correction factor of $0.23 \mathrm{mg} / \mathrm{dl}$, and (2) alignment of mean serum creatinine values from the Framingham Offspring Study by sex-specific age groups (20-39, 40-59, 60-69, and $\geq 70$ years) with the corresponding corrected NHANES III age- and sex-specific means [41]. The CKD-EPI equation was used to estimate the glomerular filtration rate (eGFR) [42]. Incident eGFR $<60$ was defined as the presence of an eGFR $<60 \mathrm{ml} / \mathrm{min} / 1.73 \mathrm{~m}^{2}$ at the eighth examination (follow-up) among participants with eGFR $\geq 60 \mathrm{ml} /$ $\mathrm{min} / 1.73 \mathrm{~m}^{2}$ at the seventh examination (baseline). The average annual rate of change in eGFR during follow-up was determined by dividing the difference in eGFR by the number of years of follow-up between the seventh and eighth examinations. Rapid eGFR decline was defined as an annual decrease in eGFR of at least $3 \mathrm{ml} /$ $\mathrm{min} / 1.73 \mathrm{~m}^{2}$ per year. In sensitivity analyses, a secondary rapid eGFR decline outcome was defined by a combination of (1) an annual decrease in eGFR of at least $3 \mathrm{ml} / \mathrm{min} / 1.73 \mathrm{~m}^{2}$ per year, and (2) incident eGFR $<60 \mathrm{ml} / \mathrm{min} / 1.73 \mathrm{~m}^{2}$ at follow-up.

\section{Additional Covariate Assessment}

Body mass index $\left(\mathrm{BMI}, \mathrm{kg} / \mathrm{m}^{2}\right)$ was calculated using weight and height measurements collected during the baseline clinic exam. Diabetes was defined as baseline plasma fasting glucose $\geq 126 \mathrm{mg} /$ $\mathrm{dl}$ or use of oral hypoglycemic agents or insulin. The presence of dipstick proteinuria at baseline was defined as a measurement of trace protein or higher in a spot urine sample.

Lifestyle Factors and Kidney Function in the Framingham Heart Study

\section{Statistical Analyses}

Incident eGFR $<60$ and rapid eGFR decline were each modeled as functions of individual lifestyle factors using logistic regression in primary and sensitivity analyses. Models were initially adjusted for age, sex, and baseline eGFR and included diet quality (DGAI, expressed as indicator variables for quartiles), physical activity (PAI, expressed as indicator variables for quartiles), current smoking status, and alcohol intake (indicator variables for low-to-moderate and high alcohol intake, with no intake as the reference group, Model 1). Models were further adjusted for baseline BMI, hypertension, diabetes, and dipstick proteinuria (Model 2). We tested for linear trends across diet quality and physical activity quartiles by performing the models described earlier with diet quality and physical activity expressed as 4-level ordinal variables. Statistical analyses were performed using SAS version 9.2 (SAS Institute, http://www.sas.com/).

\section{Results}

\section{Lifestyle Factors and Incident eGFR $<60$ \\ $\mathrm{ml} / \mathrm{min} / 1.73 \mathrm{~m}^{2}$}

Overall, $54.8 \%$ of our study sample participants were women with an average baseline age of 59; additional baseline characteristics are presented in table 1. Participants were overweight on average (mean BMI of $28.0 \mathrm{~kg} / \mathrm{m}^{2}$ ), 
Table 2. Odds ratios and $95 \% \mathrm{CI}$ of incident eGFR $<60 \mathrm{ml} / \mathrm{min} / 1.73 \mathrm{~m}^{2}(\mathrm{n}=1,802)$ and estimated using the CKD-EPI equation, by lifestyle exposures

\begin{tabular}{|c|c|c|c|c|}
\hline & \multicolumn{2}{|l|}{ Model $1^{\dagger}$} & \multicolumn{2}{|l|}{ Model 2* } \\
\hline Q1 - lowest quality & 1.00 (ref) & - & 1.00 (ref) & \\
\hline Q2 & $0.80(0.49-1.30)$ & 0.37 & $0.77(0.47-1.27)$ & 0.30 \\
\hline Q3 & $0.55(0.33-0.92)$ & 0.02 & $0.52(0.31-0.89)$ & 0.02 \\
\hline \multicolumn{5}{|l|}{ Physical activity index } \\
\hline Q1 - lowest activity & 1.00 (ref) & - & 1.00 (ref) & \\
\hline Q2 & $1.12(0.67-1.90)$ & 0.66 & $1.16(0.69-1.97)$ & 0.58 \\
\hline Q3 & $1.10(0.66-1.86)$ & 0.71 & $1.07(0.63-1.81)$ & 0.80 \\
\hline Q4 - highest activity & $1.23(0.74-2.04)$ & 0.42 & $1.19(0.71-1.99)$ & 0.51 \\
\hline $\mathrm{p}$ trend & & 0.46 & & 0.60 \\
\hline None & 1.00 (ref) & - & 1.00 (ref) & \\
\hline Low-to-moderate & $0.84(0.57-1.24)$ & 0.39 & $0.94(0.63-1.40)$ & 0.75 \\
\hline High & $0.83(0.49-1.40)$ & 0.48 & $0.84(0.49-1.43)$ & 0.51 \\
\hline
\end{tabular}

${ }^{\dagger}$ Adjusted for other listed lifestyle factors, age, sex, and baseline eGFR. * Adjusted for other listed lifestyle factors, age, sex, baseline eGFR, BMI, hypertension, diabetes, and dipstick proteinuria. Q = Quartiles; CI = confidence intervals.

Table 3. Odds ratios and $95 \% \mathrm{CI}$ of rapid eGFR decline $\geq 3 \mathrm{ml} / \mathrm{min} / 1.73 \mathrm{~m}^{2}$ per year $(\mathrm{n}=1,964)$, defined using eGFR estimated using the CKD-EPI equation, by lifestyle exposures

\begin{tabular}{|c|c|c|c|c|}
\hline & \multicolumn{2}{|l|}{ Model $1^{\dagger}$} & \multicolumn{2}{|l|}{ Model 2* } \\
\hline Q1 - lowest quality & 1.00 (ref) & - & 1.00 (ref) & - \\
\hline Q2 & $0.82(0.56-1.20)$ & 0.31 & $0.83(0.56-1.22)$ & 0.34 \\
\hline Q3 & $0.70(0.47-1.04)$ & 0.08 & $0.73(0.49-1.10)$ & 0.13 \\
\hline \multicolumn{5}{|l|}{ Physical activity index } \\
\hline Q1 - lowest activity & 1.00 (ref) & - & 1.00 (ref) & - \\
\hline Q2 & $1.26(0.85-1.85)$ & 0.25 & $1.30(0.88-1.93)$ & 0.19 \\
\hline Q3 & $1.23(0.84-1.81)$ & 0.29 & $1.23(0.83-1.82)$ & 0.31 \\
\hline Q4 - highest activity & $0.88(0.58-1.32)$ & 0.53 & $0.93(0.61-1.42)$ & 0.73 \\
\hline $\mathrm{p}$ trend & & 0.57 & & 0.72 \\
\hline None & 1.00 (ref) & - & 1.00 (ref) & - \\
\hline Low-to-moderate & $0.87(0.64-1.20)$ & 0.39 & $0.99(0.71-1.37)$ & 0.94 \\
\hline High & $1.01(0.68-1.50)$ & 0.98 & $1.12(0.74-1.68)$ & 0.60 \\
\hline
\end{tabular}

${ }^{\dagger}$ Adjusted for other listed lifestyle factors, age, sex, and baseline eGFR. * Adjusted for other listed lifestyle factors, age, sex, baseline eGFR, BMI, hypertension, diabetes, and dipstick proteinuria. Q = Quartiles; CI = confidence intervals. 
with a low-to-moderate level of daily physical activity and a diet quality consistent with about half of the diet recommendations reflected in the DGAI. The prevalence of current smoking was $11.9 \%$ and the majority of participants consumed either low-to-moderate levels or no alcohol.

During follow-up (mean of 6.6 years), 9.5\% $(n=171)$ participants developed incident eGFR $<60$. After accounting for age, sex, baseline eGFR, physical activity, alcohol intake, and current smoking, we observed a significant trend across diet quality quartiles suggesting that higher diet quality associated with a decreased odds of incident eGFR $<60$ ( $p$ trend $=0.045$; table 2 ). These results were similar after further adjustment for BMI, hypertension, diabetes, and dipstick proteinuria (table 2). In contrast, we did not observe associations with physical activity, smoking status, or alcohol intake with incident eGFR $<60$ (all p > 0.39; table 2).

\section{Lifestyle Factors and Rapid eGFR Decline}

During follow-up, $12.1 \%(\mathrm{n}=238$ of 1,964$)$ of participants experienced rapid eGFR decline (primary definition of eGFR decline $\geq 3 \mathrm{ml} / \mathrm{min} / 1.73 \mathrm{~m}^{2}$ per year). Similar to incident eGFR $<60$, a significant trend was observed across diet quality quartiles ( $\mathrm{p}$ trend $=0.03$ ), and the highest diet quality quartile was associated with a decreased odds of rapid eGFR decline after accounting for age, sex, baseline eGFR and the other lifestyle factors (table 3, Quartile 4 vs. Quartile 1: OR 0.65, 95\% CI 0.43-0.98, $\mathrm{p}=0.04$ ). The associations of diet quality with rapid eGFR decline were attenuated with additional adjustment for BMI, hypertension, diabetes, and dipstick proteinuria ( $\mathrm{p}$ trend $=0.07$ ). However, in sensitivity analyses when the analysis was repeated with a stricter definition of rapid eGFR decline (eGFR decline $\geq 3 \mathrm{ml} / \mathrm{min} / 1.73 \mathrm{~m}^{2}$ per year and eGFR $<60$ $\mathrm{ml} / \mathrm{min} / 1.73 \mathrm{~m}^{2}$ at follow-up; $\mathrm{n}=80$ cases $/ 1,722$ controls), the inverse association between increasing diet quality and decreasing odds of rapid eGFR decline remained significant and was robust to adjustment ( $\mathrm{p}$ trend $=0.02$ and $p$ trend $=0.04$; online suppl. table 1, www.karger.com/ doi/10.1159/000430868). Physical activity, current smoking, and alcohol consumption were not significantly associated with rapid eGFR decline in primary (table 3) or sensitivity analyses (online suppl. table 1).

\section{Discussion}

Among Framingham Offspring participants, our findings suggest that higher diet quality is associated with a decreased risk of developing incident eGFR $<60 \mathrm{ml} /$ $\min / 1.73 \mathrm{~m}^{2}$ and rapid eGFR decline after a mean of 6.6 years of follow-up. These findings were not materially different after accounting for BMI, diabetes, hypertension, and proteinuria, suggesting that the decreased risk is not fully attributable to the potential association of higher diet quality with obesity and cardio-metabolic diseases. In contrast, other lifestyle characteristics, including physical activity, smoking, and alcohol intake, were not associated with developing incident eGFR $<60$ or rapid eGFR decline over the same time period.

While recent studies have reported on the role of specific nutrient intake and the development of incident eGFR $<60[24-26,36]$, limited data addressing the association of overall diet quality or dietary patterns and renal function are available [22, 23]. Adherence to a Mediterranean dietary pattern and creatinine clearance were assessed in a cross-sectional sample of individuals aged 1889 in Greece, with higher adherence associated with a higher creatinine clearance [23]. In a sample of $\sim 3,000$ women from the Nurses' Health Study, an overall diet consistent with a Western diet pattern was associated with an increased risk of rapid eGFR decline, whereas a diet consistent with a Dietary Approach to Hypertension (DASH) diet pattern was associated with a decreased risk of rapid eGFR decline [22]. Our findings extend the current literature to suggest that beneficial dietary associations observed for other diseases include diabetes and cardiovascular disease $[43,44]$. This may also extend to incident eGFR $<60$ and rapid eGFR decline.

Our results indicate that physical activity levels are not associated with incident eGFR $<60$ in our study sample selected from Framingham Offspring participants. In the Australian Diabetes, Obesity and Lifestyle (AusDiab) Study, when compared to participants reporting sufficient leisure-time physical activity ( $\geq 150 \mathrm{~min} /$ week), participants who were inactive or insufficiently active ( $>0$ but $<150 \mathrm{~min} /$ week) were not at increased risk of developing de novo low eGFR [27]. In relation to rapid eGFR decline, no consistent trend was observed with higher levels of physical activity. In contrast, among older adults in the Cardiovascular Health Study, a higher physical activity score (based on leisure-time activity and walk pace) was associated with a decreased risk of rapid eGFR decline over 7 years follow-up [28]. Similarly, physical activity during non-working hours was associated with an increase in eGFR when compared to physical inactivity after 7 years of follow-up among women in the Tromso study [29]. Our disparate findings may be attributable to differences in exposure assessment (leisure-time physical activity vs. overall physical activity) or study population demographics; for 
example, the CHS study sample participants were on average older than the participants in the present analysis.

The association of alcohol intake and changes in renal function has been investigated previously in prospective analyses, with conflicting results. Moderate alcohol consumption was [22] not associated with declining renal function over 11 years follow-up in the Nurses' Health Study [30] and alcohol consumption was not associated with rapid eGFR decline in the CHS [31], whereas results from the Beaver Dam Study suggest that heavy alcohol intake ( $\geq 4$ drinks/day) is associated with an elevated risk of developing CKD over 5 years [32]. Protective associations have also been reported in other study populations. Among men in the AusDiab Study, a protective association for de novo low eGFR was observed for moderate-toheavy alcohol consumption when compared to light consumption; among current drinkers, a protective association was also observed for consuming $\geq 30 \mathrm{~g} /$ day when compared to $<10 \mathrm{~g} /$ day [33]. High alcohol consumption among men in the Tromso study was also associated with an increase in eGFR over 7 years of follow-up when compared to alcohol abstention [29]. A protective association for moderate alcohol consumption and CKD has also been observed over 10-years follow-up in a communitybased sample from Japan [34] ( $<20 \mathrm{~g} /$ day) as well over 14 years follow-up in the Physicians' Health Study, with consumption of $\geq 7$ drinks/week associated with a decreased risk of reduced eGFR [35]. We did not observe a significant association between alcohol intake, incident eGFR $<60$, or rapid eGFR decline, although our results were suggestive of a protective effect of low-to-moderate or high alcohol intake when compared to non-drinkers.

Our current smoking results are in contrast to our previous report in the Framingham Offspring cohort, in which we observed that current smoking is a risk factor for incident eGFR $<60$ after 18.5 years of follow-up [5], whereas in the present analysis we observed that current smoking at baseline was not associated with incident eGFR $<60$ or rapid eGFR decline after 6.6 years of followup. Our disparate results may be due to differences in baseline study samples and length of follow-up. Specifically, our prior study consisted of individuals with a mean age of 42 and a smoking prevalence of $33 \%$ [5], whereas the present study consists of surviving participants nearly two decades later (and therefore two decades older) who by then had a lower smoking prevalence of $11.9 \%$. Additionally, the follow-up period was shorter in the present analysis (6.6 vs. 18.5 years), and this may not be long enough to capture the effect of smoking on renal function decline.
We assessed the diet quality using the DGAI: a summary score that takes into account eleven food-specific intake recommendations as well as nine 'healthy choice' recommendations in the 2005 Dietary Guidelines for Americans [38]. Higher diet quality assessed by DGAI indicates dietary intake consistent with recommended intakes of fruits and vegetables, meat and legumes, dairy, whole grains and fiber, sodium, alcohol, and discretionary energy intake based on dietary patterns defined by estimated energy requirements. Additional penalties for overconsumption of energy-dense foods (high in fats and sugars) are also included in the score. Higher scores reflect better adherence to recommended levels of intake and greater variety of intake within each food group. DGA recommendations for foods higher in proteins may result in protein intakes that exceed levels indicated by the KDOQI nutrition guidelines for individuals with mild kidney disease; however, sources of protein encouraged are similar to the DASH diet [22] - vegetable, low-fat dairy, whole grains, nuts, legumes, fish and poultry - and have not typically been associated with decline in kidney function. Higher DGAI scores have previously been positively associated with intake of healthy food items such as fruits and vegetables and negatively associated with intake of fats and other energy-dense foods [38]. Additionally, higher DGAI scores are associated with lower levels of central adiposity [45], and decreased insulin resistance [46]. Our findings suggest that diet quality may be a modifiable kidney function risk factor among older adults that could potentially be targeted as an approach to reduce the incidence of eGFR $<60$ or rapid eGFR decline. Of note, trends persisted after accounting for baseline BMI, diabetes, hypertension, and proteinuria, suggesting that potential mechanistic pathways underlying our observed association may be independent of the impact of diet quality on obesity and these cardio-metabolic conditions. We were unable to compare the associations of diet quality and kidney function between this study and our previous study examining lifestyle factors in FHS [5] because dietary data was unavailable prior to the seventh examination. Future prospective research in a randomized setting is necessary to determine whether interventions promoting adherence to US dietary guidelines are feasible and effective in improving renal outcomes.

Strengths of the present analysis include its prospective design in a community-based sample with well-measured clinical covariates. There are several potential limitations that warrant mention. While we did observe a wide range of DGAI scores, few participants had high DGAI scores thus suggesting the association of higher di- 
etary quality and lower risk of CKD may have been even stronger among those closely adhering to the US dietary recommendations. Incident eGFR $<60$ and rapid eGFR decline were determined based on single serum creatinine measurements at baseline and end of follow-up, leading to potential outcome misclassification. However, any non-differential misclassification would tend to attenuate the true association. In addition, the inverse trend in associations observed between dietary quality and rapid eGFR decline was robust to a secondary (and a more strict) definition of rapid eGFR decline in sensitivity analysis. Furthermore, we used a spot urine dipstick test to classify proteinuria status in place of measuring urinary albumin-to-creatinine ratio. In addition, we observed significant differences for hypertension and diabetes status between participants included and excluded from the analysis based on missing dietary intake data. This suggests that the participants who were excluded based on dietary data were likely to be less healthy, and excluding these individuals from the analysis likely attenuated the true association between lifestyle factors and incident eGFR $<60$. Finally, our study sample comprised predominately of older participants of European ancestry, and the generalizability of our results to younger populations or other race or ethnic groups may be limited.

In conclusion, our findings suggest that higher diet quality is a modifiable lifestyle factor that may be associated with a decreased risk of developing incident eGFR
$<60 \mathrm{ml} / \mathrm{min} / 1.73 \mathrm{~m}^{2}$ and rapid eGFR decline. Whether improving diet quality based on the US Dietary Guidelines for Americans (or its individual food components) may lead to improved renal outcomes among older adults in the US population of European and non-European ancestral background is still in question. Our study highlighted the importance of detailed analyses of lifestyle factors and measures of kidney function, and also suggested the investigation of individual foods and food groups with kidney function for future study.

\section{Acknowledgments}

The Framingham Heart Study is supported by the National Heart, Lung, and Blood Institute (N01-HC-25195). The study sponsor did not have a role in study design, the collection, analysis, and interpretation of data, writing the report, and the decision to submit the report for publication.

\section{Financial Support}

None.

\section{Disclosure Statement}

The authors declare that there are no conflicts of interest.

\section{References}

1 Coresh J, Selvin E, Stevens LA, Manzi J, Kusek JW, Eggers P, Van Lente F, Levey AS: Prevalence of chronic kidney disease in the United States. JAMA 2007;298:2038-2047.

2 Go AS, Chertow GM, Fan D, McCulloch CE, Hsu CY: Chronic kidney disease and the risks of death, cardiovascular events, and hospitalization. N Engl J Med 2004;351: 1296-1305.

3 Anavekar NS, McMurray JJ, Velazquez EJ, Solomon SD, Kober L, Rouleau JL, White HD, Nordlander R, Maggioni A, Dickstein K, Zelenkofske S, Leimberger JD, Califf RM, Pfeffer MA: Relation between renal dysfunction and cardiovascular outcomes after myocardial infarction. N Engl J Med 2004;351: 1285-1295.

4 Weiner DE, Tighiouart H, Amin MG, Stark PC, MacLeod B, Griffith JL, Salem DN, Levey AS, Sarnak MJ: Chronic kidney disease as a risk factor for cardiovascular disease and allcause mortality: a pooled analysis of community-based studies. J Am Soc Nephrol 2004; 15:1307-1315.

Lifestyle Factors and Kidney Function in the Framingham Heart Study
5 Fox CS, Larson MG, Leip EP, Culleton B, Wilson PW, Levy D: Predictors of new-onset kidney disease in a community-based population. JAMA 2004;291:844-850.

6 Berghöfer A, Pischon T, Reinhold T, Apovian CM, Sharma AM, Willich SN: Obesity prevalence from a European perspective: a systematic review. BMC Public Health 2008;8:200.

7 Malnick SD, Knobler H: The medical complications of obesity. QJM 2006;99:565-579.

8 Flegal KM, Carroll MD, Ogden CL, Curtin LR: Prevalence and trends in obesity among US adults, 1999-2008. JAMA 2010;303:235-241.

9 Ogden CL, Yanovski SZ, Carroll MD, Flegal KM: The epidemiology of obesity. Gastroenterology 2007;132:2087-2102.

10 Iseki K, Ikemiya Y, Kinjo K, Inoue T, Iseki C, Takishita S: Body mass index and the risk of development of end-stage renal disease in a screened cohort. Kidney Int 2004;65:18701876.

11 Gelber RP, Kurth T, Kausz AT, Manson JE, Buring JE, Levey AS, Gaziano JM: Association between body mass index and CKD in appar- ently healthy men. Am J Kidney Dis 2005;46: 871-880

12 Hsu CY, McCulloch CE, Iribarren C, Darbinian J, Go AS: Body mass index and risk for end-stage renal disease. Ann Intern Med 2006; 144:21-28.

13 Foster MC, Hwang SJ, Larson MG, Lichtman JH, Parikh NI, Vasan RS, Levy D, Fox CS: Overweight, obesity, and the development of stage $3 \mathrm{CKD}$ : the Framingham heart study. Am J Kidney Dis 2008;52:39-48.

14 Chen J, Muntner P, Hamm LL, Jones DW, Batuman V, Fonseca V, Whelton PK, He J: The metabolic syndrome and chronic kidney disease in U.S. adults. Ann Intern Med 2004;140:167-174

15 Elsayed EF, Sarnak MJ, Tighiouart H, Griffith JL, Kurth T, Salem DN, Levey AS, Weiner DE: Waist-to-hip ratio, body mass index, and subsequent kidney disease and death. Am J Kidney Dis 2008;52:29-38.

16 Savage S, Nagel NJ, Estacio RO, Lukken N, Schrier RW: Clinical factors associated with urinary albumin excretion in type II diabetes. Am J Kidney Dis 1995;25:836-844. 
17 Tapp RJ, Shaw JE, Zimmet PZ, Balkau B, Chadban SJ, Tonkin AM, Welborn TA, Atkins RC: Albuminuria is evident in the early stages of diabetes onset: results from the Australian diabetes, obesity, and lifestyle study (AusDiab). Am J Kidney Dis 2004;44:792-798.

18 Chandie Shaw PK, Berger SP, Mallat M, Frölich M, Dekker FW, Rabelink TJ: Central obesity is an independent risk factor for albuminuria in nondiabetic South Asian subjects. Diabetes Care 2007;30:1840-1844.

19 de Boer IH, Sibley SD, Kestenbaum B, Sampson JN, Young B, Cleary PA, Steffes MW, Weiss NS, Brunzell JD: Central obesity, incident microalbuminuria, and change in creatinine clearance in the epidemiology of diabetes interventions and complications study. J Am Soc Nephrol 2007; 18:235-243.

20 Pinto-Sietsma SJ, Navis G, Janssen WM, de Zeeuw D, Gans RO, de Jong PE: A central body fat distribution is related to renal function impairment, even in lean subjects. Am J Kidney Dis 2003;41:733-741.

21 Foster MC, Hwang SJ, Porter SA, Massaro JM, Hoffmann U, Fox CS: Fatty kidney, hypertension, and chronic kidney disease: the Framingham heart study. Hypertension 2011;58: 784-790.

22 Lin J, Fung TT, Hu FB, Curhan GC: Association of dietary patterns with albuminuria and kidney function decline in older white women: a subgroup analysis from the nurses' health study. Am J Kidney Dis 2011;57:245-254.

23 Chrysohoou C, Panagiotakos DB, Pitsavos C, Skoumas J, Zeimbekis A, Kastorini CM, Stefanadis C: Adherence to the Mediterranean diet is associated with renal function among healthy adults: the ATTICA study. J Ren Nutr 2010;20:176-184.

24 Gopinath B, Harris DC, Flood VM, Burlutsky G, Brand-Miller J, Mitchell P: Carbohydrate nutrition is associated with the 5-year incidence of chronic kidney disease. J Nutr 2011; 141:433-439.

25 Gopinath B, Harris DC, Flood VM, Burlutsky G, Mitchell P: Consumption of long-chain n-3 PUFA, $\alpha$-linolenic acid and fish is associated with the prevalence of chronic kidney disease. Br J Nutr 2011;105:1361-1368.

26 Bomback AS, Derebail VK, Shoham DA, Anderson CA, Steffen LM, Rosamond WD, Kshirsagar AV: Sugar-sweetened soda con- sumption, hyperuricemia, and kidney disease. Kidney Int 2010;77:609-616.

27 White SL, Dunstan DW, Polkinghorne KR, Atkins RC, Cass A, Chadban SJ: Physical inactivity and chronic kidney disease in Australian adults: the AusDiab study. Nutr Metab Cardiovasc Dis 2011;21:104-112.

28 Robinson-Cohen C, Katz R, Mozaffarian D, Dalrymple LS, de Boer I, Sarnak M, Shlipak M, Siscovick D, Kestenbaum B: Physical activity and rapid decline in kidney function among older adults. Arch Intern Med 2009; 169:2116-2123

29 Kronborg J, Solbu M, Njølstad I, Toft I, Eriksen BO, Jenssen T: Predictors of change in estimated GFR: a population-based 7-year follow-up from the Tromso study. Nephrol Dial Transplant 2008;23:2818-2826.

30 Knight EL, Stampfer MJ, Rimm EB, Hankinson SE, Curhan GC: Moderate alcohol intake and renal function decline in women: a prospective study. Nephrol Dial Transplant 2003; 18:1549-1554.

31 Menon V, Katz R, Mukamal K, Kestenbaum B, de Boer IH, Siscovick DS, Sarnak MJ, Shlipak MG: Alcohol consumption and kidney function decline in the elderly: alcohol and kidney disease. Nephrol Dial Transplant 2010;25:3301-3307.

32 Shankar A, Klein R, Klein BE: The association among smoking, heavy drinking, and chronic kidney disease. Am J Epidemiol 2006;164: 263-271.

33 White SL, Polkinghorne KR, Cass A, Shaw JE, Atkins RC, Chadban SJ: Alcohol consumption and 5-year onset of chronic kidney disease: the AusDiab study. Nephrol Dial Transplant 2009;24:2464-2472.

34 Yamagata K, Ishida K, Sairenchi T, Takahashi H, Ohba S, Shiigai T, Narita M, Koyama A: Risk factors for chronic kidney disease in a community-based population: a 10-year follow-up study. Kidney Int 2007;71:159166.

35 Schaeffner ES, Kurth T, de Jong PE, Glynn RJ, Buring JE, Gaziano JM: Alcohol consumption and the risk of renal dysfunction in apparently healthy men. Arch Intern Med 2005;165: 1048-1053.

36 Ritz E, Schwenger V: Lifestyle modification and progressive renal failure. Nephrology (Carlton) 2005;10:387-392.
37 Rimm EB, Giovannucci EL, Stampfer MJ Colditz GA, Litin LB, Willett WC: Reproducibility and validity of an expanded self-administered semiquantitative food frequency questionnaire among male health professionals. Am J Epidemiol 1992;135:1114-1126; discussion 1127-1136.

38 Fogli-Cawley JJ, Dwyer JT, Saltzman E, McCullough ML, Troy LM, Jacques PF: The 2005 dietary guidelines for Americans adherence index: development and application. J Nutr 2006;136:2908-2915.

39 Kannel WB, Sorlie P: Some health benefits of physical activity. The Framingham study. Arch Intern Med 1979;139:857-861.

40 U.S. Department of Agriculture; U.S. Department of Health and Human Services: Dietary Guidelines for Americans 2010, ed 7, Washington, DC, U.S. Government Printing Office, 2010.

41 Coresh J, Astor BC, McQuillan G, Kusek J, Greene T, Van Lente F, Levey AS: Calibration and random variation of the serum creatinine assay as critical elements of using equations to estimate glomerular filtration rate. Am J Kidney Dis 2002;39:920-929.

42 Levey AS, Stevens LA, Schmid CH, Zhang YL Castro AF 3rd, Feldman HI, Kusek JW, Eggers P, Van Lente F, Greene T, Coresh J: A new equation to estimate glomerular filtration rate. Ann Intern Med 2009;150:604-612.

$43 \mathrm{Hu}$ FB, Rimm EB, Stampfer MJ, Ascherio A, Spiegelman D, Willett WC: Prospective study of major dietary patterns and risk of coronary heart disease in men. Am J Clin Nutr 2000;72: 912-921.

44 Salas-Salvadó J, Martinez-González MÁ, Bulló $\mathrm{M}$, Ros $\mathrm{E}$ : The role of diet in the prevention of type 2 diabetes. Nutr Metab Cardiovasc Dis 2011;21(suppl 2):B32-B48.

45 Molenaar EA, Massaro JM, Jacques PF, Pou KM, Ellison RC, Hoffmann U, Pencina K, Shadwick SD, Vasan RS, O’Donnell CJ, Fox CS: Association of lifestyle factors with abdominal subcutaneous and visceral adiposity: the Framingham heart study. Diabetes Care 2009;32:505-510.

46 Fogli-Cawley JJ, Dwyer JT, Saltzman E, McCullough ML, Troy LM, Meigs JB, Jacques PF: The 2005 dietary guidelines for Americans and insulin resistance in the Framingham Offspring cohort. Diabetes Care 2007;30:817-822. 